This item was submitted to Loughborough's Research Repository by the author.

Items in Figshare are protected by copyright, with all rights reserved, unless otherwise indicated.

\title{
Editorial: The cybernetic return in human factors and ergonomics
}

PLEASE CITE THE PUBLISHED VERSION

https://doi.org/10.1016/j.apergo.2019.01.011

PUBLISHER

(c) Elsevier

VERSION

AM (Accepted Manuscript)

PUBLISHER STATEMENT

This paper was accepted for publication in the journal Applied Ergonomics and the definitive published version is available at https://doi.org/10.1016/j.apergo.2019.01.011

\section{LICENCE}

CC BY-NC-ND 4.0

\section{REPOSITORY RECORD}

Baber, Chris, David Golightly, and Patrick Waterson. 2019. "Editorial: The Cybernetic Return in Human Factors and Ergonomics". figshare. https://hdl.handle.net/2134/38124. 


\section{The Cybernetic Return in Human Factors and Ergonomics}

\section{Introduction}

Ergonomics has always been concerned with the study of systems and has developed over the course of fifty or so years a range of methods which allow systems to be described and analysed (Edwards and Lee, 1974; Kleiner and Hendrick, 2002; Wilson, 2014). However, we would argue that perennial problems relate to the study of systems that change with time and to systems which have many interacting components. These issues, of dynamics and complexity, becoming increasingly relevant to contemporary concerns with large-scale transport, safety-critical or medical systems, but are equally applicable to smaller systems. Consequently, there is a need to develop and extend methods which allow analysts to describe, analyse and make predictions about complex, dynamic systems. Such a concern is not new, however, and its roots can be traced back to the cybernetics movement of the 1950s and 1960s. Human Factors shares these roots and associated concerns with the notion of 'system' but has either lost touch with some of the quantitative approaches that developed from cybernetics, or has failed to grasp the implications of new analysis techniques that have developed from the studies of complex systems in other domains.

\section{Origins of the special issue}

At the 2016 UK Chartered Institute of Ergonomics and Human Factors (CIEHF) conference, Patrick Waterson, David Golightly and Chris Baber ran a panel session called 'the cybernetic return'. We had noted a growing trend in the Ergonomics community towards quantification and modelling of Systems in a manner that is reminiscent of cybernetics approaches of the past. Alongside quantitative methods which draw on earlier cybernetic research, we were also aware of a trend towards the use of qualitative methods, again with their roots in cybernetic theory (e.g., control theory) which were being used to model complex systems. This panel was well attended and suggests that there would be interest in a special issue along these lines. In 2013, Baber gave the Donald Broadbent lecture (again to the CIEHF conference) in which he argued for the need to understand how systems change over time and for the Ergonomics community to move away from the static snapshots of systems that we present in 'boxology'. Again, this provoked some debate and highlighted the value in collecting papers together exploring these notions regarding systems.

The broad themes of a cybernetic approach that we think are of interest, range from the notion of requisite variety (in which the control of a system requires a model that can cope with the complexity of the environment in which it is operating), the notion that systems monitor and manage specific critical parameters and that they do this is order to maintain stability of target states. From this, one can ask, what are the parameters that a system appears to be controlling, and what target states does the system appear to emphasise? Understanding these questions could help Human Factors explain how systems are behaving in a suboptimal manner, e.g., a system which is intended to allow rapid throughput of patients or travellers could actually (because of constraints on its operation) be shown to be seeking extended delays and disruptions. This special issue addresses the contemporary impacts of Dynamic Systems / Systems Dynamics models, methods and thinking on Ergonomics. These concern the ways in which ideas developed back in the days of cybernetics are finding their way into the systems thinking of modern Ergonomics, and how this can result in quantitative methods which can make predictions about, or explain, emergence in complex systems. In particular, we are interested in the ways in which systems can be described in terms of how they change of time and in methods and techniques which allow us to quantify system activity. 


\section{A brief history of cybernetics}

The term 'cybernetics' derives from the Greek word 'kybernētēs' and is usually translated as meaning 'steersman', 'governor' or 'pilot'. One of the pioneers of cybernetics, Norbert Wiener, defined the discipline as 'the science of control and communication in man and machine' (Wiener, 1948). Cybernetics reached its heyday in the period immediately following World War II. As a discipline, cybernetics grew out of the various approaches that were involved in managing ballistics and weapons systems. The fundamental observation was that a 'system' could be defined in terms of a steady state (or set of states) around which behaviour could be constrained. This meant that it was important to define the desired state and to have some means of measuring the current state so that this could be compared with the desired state (in order to make some corrective action when deviation arose). Thus, the key issue concerned the measurement of difference and a central conception was that any system would have a finite number of states that could be differentiated from each other. Ashby (1956) called this number of states the variety of a system, which led him to propose a Law of Requisite Variety: "A controller has requisite variety when he has the capacity to maintain the outcomes of a process within targets, if and only if he has the capacity to produce response to all those disturbances that influence the process". Broadly, this means that there is a need to sample the system's states in order to detect disturbances (which are departures from desired settings for each state) and a need to respond appropriately to any of these disturbances. While this is a simple concept which can be represented as a feedback loop from an output measure to a comparator, it could be applied to a wide range of settings, and sought to describe people, machines and organisations in terms of 'servocontrol mechanisms'. Hence, it is often thought of the First Law of Cybernetics.

Early cybernetics was closely aligned with biology and sought to provide a better understanding of how the brain works. Critically, this involved linking not only brain function with thinking, but also with action and the design of thinking machines: 'To some, the critical test of whether a machine is or is not a 'brain' would be whether it can or cannot 'think'. But to the biologist the brain is not a thinking machine, it is an acting machine; it gets information and then it does something about it' (Ashby, 1948, p. 379). Cyberneticians at this time conceived at this time the brain as an embodied organ, intrinsically tied into bodily performances (Pickering, 2010). This link between thought and action is reflected in some of the papers in the special issue and represents the backdrop for many debates and discussions with the field of embodied cognition and the extended mind (e.g., Clark, 2008).

Later developments in the 1960s and 70s are sometimes labelled 'second order cybernetics' and involved widening the scope and scale of systems which were subject to observation and study. These types of systems included environmental, educational and social systems and involved the application of concepts such as 'autopoesis' (self-organisation), 'self referentiality' and emergent coupling between macro and macro parts of systems such as manufacturing plants and larger political and economic systems. Bateson (1972) for example, examined homeostatic processes within social groups and how this might be influenced by the biophysical environment in which they lived. Pask (1975) by contrast used cybernetics as a basis with which to develop his 'conversation theory' and apply this to the development of early forms of computer-aided instructional systems. A final and important point to note is that many of these individuals took part in and were active in the meetings which took place in the late 1940s/early 1950s and led on to the development of the Ergonomics Society in the UK and Human Factors Society in the USA (Waterson, 2011). The 'Ratio Club' for example, involved a diverse group of mathematicians, biologists, psychiatrists, engineers and psychologists which met regularly in the late 1940s in London in order to discuss and present papers on cybernetic topics (Husbands and Holland, 2008). Many of the people who attended these meetings would go on to form the Ergonomics Society in 1949. The continued overlap between cybernetics and ergonomics is also reflected in the fact that at Loughborough the 'Department of Ergonomics and Cybernetics' existed up the early 1970s (Anon., 1971). 


\section{Why is there a cybernetic return'?}

Ergonomics has always been confronted with complex systems. Complexity arises from the many-tomany mapping that relate causes to effects in changing environments. We address such complexity with the fundamental concept that we need to understand and explain the 'system'. With the need to better understand the ways in which healthcare or transport systems operate, fail or will evolve, there is an imperative on Ergonomics to ensure that its conception of systems is fit for purpose. The very idea of a system comes from cybernetics.

\section{Two examples of contemporary cybernetic systems}

\section{Healthcare}

The field of healthcare is often characterised as a complex, adaptive sociotechnical system (e,g,, Plsek and Greenhalgh, 2001; Braithwaite, 2018). Part of the reason is that delivering safe and cost-effective healthcare involves a diverse range of stakeholders ranging from patients though to the many different specialisms, technologies (nurses, doctors, managers) and organisations/agencies involved. In addition, the way in which healthcare is delivered is dependent on national and local policies, as well as most critically aspects of the organisational culture of the healthcare delivery organisation, workgroup, as well professional norms and practices which have developed over time. Because of the pressure on healthcare systems such as the UK National Health Service (NHS) healthcare organisations and staff have to continually adapt to new circumstances and demands. Likewise, interactions between sub-components within the larger healthcare system are often nonlinear, unpredictable and have fuzzy boundaries. The delivery of what on the face of it may appear to be a relatively simple sets of task involved in elective orthopaedic surgery for example, may involve a large range of healthcare agencies (e.g., primary care, community, paramedic and acute healthcare providers, technologies (e.., electronic patient records), artefacts (e.g., paper-based records) and patient-centred factors (e.g.. age, medical condition and fitness, presence of carers - Eason and Waterson, 2014). All of these factors make healthcare complex and to use terms associated with resilience engineering, 'brittle' and 'fragile' (Hollnagel et al., 2013).

Viewing healthcare through the lens of cybernetics might be a useful exercise for a number of reasons. One of these is that healthcare accidents and disasters rarely occur in the manner in which they occur in other high-risk domains (e.g., the nuclear, oil and gas industries). Rather than a single explosion or a set of component failures, many accidents in healthcare take many years to be recognised and acknowledged. The recent investigation into the high number of maternal deaths at NHS Morecambe Bay Trust for example (Kirkup, 2015), established a pattern of failure over almost a decade (20042013). The report concluded that to many dysfunctional aspects of maternity care delivery at the Trust including poor working relationships between staff (e.g., midwives and obstetricians), poor clinical governance and inadequate investigation processes, both within the Trust and outside, had contributed to the disaster. During 2014-13 NHS Morecambe Bay Trust had, in a phrase borrowed from Dekker (2011), 'drifted into failure'. In many ways this sort of disaster is ripe for a cybernetic analysis. Beer (1972) for example, put forward the Viable Systems Model (VSM) in order to demonstrate how systems self-organise themselves and achieve a state of stability through aligning internal complexity with the external complexity of the environment in which they operate. At the heart of these concerns was a consideration of levels of analysis and in the case of the VSM this mapped on to a set of interacting subsystems which mapped onto aspects of organizational structure (e.g., operational management, policy-making and strategy). This approach to understanding levels is also reflected in more recent work which adopts a systemic approach towards safety and accidents (e.g., Leveson's work on the STAMP methodology, Leveson, 2012). The VSM might be a useful method for understanding how the various components (e.g., hospital units), organisations (e.g., Trust 
managers, regulators) and agents (e.g., midwives and other maternity specialisms) move into an out of the boundaries of safety and gradually degraded over time. The analysis might also yield points in time when the Trust had an opportunity to 'right itself' and achieve stability. Use of VSM and other cybernetics methods, models might be one way forward in understanding what Turner (1978) characterised as the 'aetiology of disaster'.

\section{Rail operations}

Taken as a whole, the railways are a typical, and complex, sociotechnical system (Wilson et al., 2007; Wilson, 2014). One key aspect of the railway operations receiving increasing focus in Ergonomics is disruption management. The challenge for railway operators is to maintain service levels particularly during disruptive events such as weather-related events, asset failures or trespass onto the railway. Such events require multiple, interlinked control actions across functions, locations and people to rectify the fault, develop and deliver contingency plans, and to communicate changes to the service to passengers (Farrington-Darby et al., 2007; Golightly et al, 2013; Schipper, 2017). Successfully executing disruption management can be the difference between a disruption being contained temporally and geographically, or it having widespread effect across the network with damaging implications for performance, delay costs (Burr et al., 2008) and for passenger perceptions (ORR, 2016).

Up to the current time, managing disruption has been a primarily manual task, in that coordination between multiple parties is through verbal communication, and problem solving is dependent on the expertise of decision-makers, with little technical support (Farrington-Darby et al., 2007). This is changing, with the promise of a range of decision support aids, including the introduction of Traffic Management Systems, and greater colocation of roles. Understanding how to both optimise current manual processes, and design and deploy new technologies, are pressing concerns which require the input of Ergonomics for considerations such as Human-Machine Interface for individual and shared understanding, the user-centred design of traffic control automation, and to support the design and configuration of team working.

There is to date, however, no comprehensive framework for describing and designing traffic control and disruption management as a socio-technical system. Nonetheless, it is a configuration of functions, often self-organised over time, to deliver control and coordination. As a domain, rail disruption should therefore be amenable to description under core cybernetic notions such as the fundamental role of control in human systems (Wiener, 1954), describing and controlling systems in terms of their requisite variety (Ashby, 1956) and that the true purpose of a system is emergent from what it does, not necessarily the intentions of designers, operators or management (Beer, 1981). This cybernetic influence can also be felt through more recent developments such as control operating through targeting multiple, concurrent levels (Hollnagel and Woods, 2005).

Cybernetics therefore continues to offer three important contributions to our understanding of the operation of the railways. The first contribution is that cybernetics offers meaning, in that the concepts offered by Ashby, Weiner, Beer and others allow us to interpret the rail disruption domain, and links phenomenon to an underpinning ontology organised around control. For example, the guiding notion of requisite variety has proved vital in work to understand the range of factors or variables beyond simply 'the timetable' when control staff seek to manage a disruption event (Golightly and Dadashi, 2017). This mapping of variety is essential to fully understand what an operator must consider jointly with any automated disruption management support, which is likely to be far more limited in the number of variables it manages as inputs and outputs, if together they are to form an effective regulator of the system. We might also consider the relaxation principle (Beer, 1975) for disruption management - what is the ideal relaxation time after an event, and what happens if the principle is violated. 
Second, cybernetics and views of complexity offers structure in that the core concepts of cybernetics allow us to specifically interpret data related to disruption. For example, driving incidents such as failure to call at stations and signals passed at danger may have no immediate technical cause, but appear to be triggered by other earlier, unrelated operational disturbances (e.g. a delay leaving a station earlier in the journey, running late behind another train) (Madigan et al., 2016). In the same way, Karwowski et al (this issue) find that minor early disturbances in system state can lead to substantial, chaotic variations in performance in later states. Both in terms of modelling and theory, the non-linear dynamics approach, applied by Karwowski could well shed light on understanding and mitigating the causes and impact of minor driving incidents.

Third, the cybernetic approach offers value. While a cybernetic orientation is often taken in regards to rail safety (e.g. Waterson et al, 2016; Li et al, this issue), there is also an important role for the cybernetic view to understand non-safety system performance. For example, it would be possible to demonstrate brittleness as well as resilience in disruption management strategies and configurations of control staff, in a manner similar to Mattos et al.'s (this issue) use of system modelling. This could be measured over performance measures that are not necessarily related to safety, but are vital for the industry such as delay, delay attribution costs and customer satisfaction (ORR, 2016). More generally, the acknowledgement of multiple competing demands and goal states beyond simply 'safety' (Hancock, this issue) allows us to recognise and anticipate the implications of change and pressures, both internal and external, on delivering a punctual railway.

\section{The challenges of systems thinking and cybernetics}

'Systems thinking' is essential to the philosophy of Ergonomics. This means understanding not only the cause-effect relations between a single factor and a consequence, but also appreciating the myriad ways in which factors combine to influence causal mechanisms and consequences. Describing such many-to-many relations can be challenging and involves the capability (and methods) to take multiple views of these relations. 'Systems thinking' encourages us to seek these multiple views, and the practice of Ergonomics has always sought methods and techniques that can capture and convey this multiplicity of views. Having said this, there remains the challenge that a description of a system that conveys all of the factors that can influence its behaviour could result in diagrams that have the messy complexity of a plate of spaghetti. In many respects our response to complexity as Ergonomists should be not be to produce further complexity, rather we need to strive for a requisite level of simplicity in our analyses of systems while avoiding becoming overly reductive (Feltovich et al., 2004). In order to take these multiple views, Ergonomists need to focus their attention on essential features of the system. This raises fundamental questions for our practice, such as, how do we know that we have a complete and coherent view of these essential features? How do we know that we have no omitted a key feature or have overly focussed on one feature at the expense of other equally important ones?

One answer to these questions is that the knowledge and experience of practising Ergonomics can help us home in on key features. While this provides some reassurance, it points out that an Ergonomic analysis might only be as good as the person conducting it. And this raises all manner of problems, particularly in safety critical domains or in expert witness and legal settings. Another answer is that the methods used need to be sufficiently systematised to allow suitably qualified and experienced people to produce consistent and reliable results from the same domain of investigation, or that that we can all efficiently draw the same inferences from an analysis or representation of the domain. Thus, one benefit of 'systems thinking' is that it calls for methods that can be systematised.

'Systems thinking', and the associated methods, often involve snap-shots of a system in which the relations between components become frozen in time. While this can provide a useful overview of 
the system, it can fail to capture the ways in which the system changes over time or as a result of different factors. A similar and well recognised problem is that the outcomes from using some systems thinking methods are limited in providing a largely retrospective account of how the system (e.g., an accident in systemic accident analysis, Underwood and Waterson, 2014) functioned or malfunctioned. This is in contrast to other researchers such as the late Barry Turner (Turner, 1978) who provided ways of examining the developmental 'incubation' of disasters and accidents. It is interesting to note that Turner was himself influenced by cybernetics in his theory of disaster incubation and in his use of grounded theory as a guiding methodology in his work (Waterson and Le Coze, 2017). In some unpublished work we have also argued that cybernetic methods such as the Viable Systems Model (Beer, 1981) have the potential to model different states of 'degradation' and 'recovery' using multiple models of actual, potential and future system states (Waterson, Baber and Li, 2016).

\section{The papers in this special issue}

The papers in this Special Issue have been collected to reflect contemporary thinking of the ways in which Ergonomics can deal with the messy complexity of systems. The papers report methods that can describe the dynamics system activity, and that can explain the many-to-many mappings and nonlinear relations in such systems. These papers describe theory and concepts relating to cybernetics and complex systems, and how to express of quantify performance and system behaviour. These are across a range of domains that are of contemporary concern to Ergonomists including manufacturing, naval operations, emergency management, transport and healthcare. The papers also explicitly, or implicitly, put forward challenges for how we conceptualise systems, and Ergonomics itself, and how our conceptualisation of systems will impact major themes, such as resilient systems and automation, in the future.

Peter Hancock argues that contemporary systems involve closed feedback loops, much in the vein of cybernetic systems. However, unless we are able to understand the purpose and functioning of these loops, we can be excluded from the decisions that such systems make. To make matters worse, it is possible for these feedback loops to operate in ways that are deceptive, in that the claimed purpose might differ from the actual purpose. Furthermore, as data are gathered and systems regulated through these feedback loops, it is possible for locally optimal solutions to result of global (systemlevel) dysfunctionality. Hancock's article raises these concerns and urges the Human Factors community to further its efforts in understanding and advising on the intentional and unintentional consequences of system operations.

\section{System Descriptions}

Thierry Morineu and John Flach propose a heuristic approach to Cognitive Work Analysis that can help provide the 'big picture' of a person's role in a system by emphasising the relationship between ecological and cognitive constraints. The approach combines the Dynamic Safety Model proposed by Rasmussen (1997) with an emphasis on the interaction between cognitive and ecological constraints on work practices. Key to the approach is the emphasis on the work domain comprising of trajectories of action and interaction; working through these trajectories involve cognition and the ability to respond to changes in the task ecology. These changes are dynamic and Morineu and Flach emphasise the need to appreciate the opportunities to recognise and manage opportunities for action, using the case study of hand-over of a stressed patient in a simulated Emergency Room.

Tao Tang, Chenling Li, Maria Chatzimichailidou, Gyuchan Tan and Patrick Waterson describe the YongWen rail accident in terms of a sociotechnical system failure, using the methods of SystemsTheoretical Accident Model and Processes (STAMP) and Human Factors Analysis and Classification System (HFACS). The relations between components that STAMP helps to identify can form the basis of a Systems Dynamic model and this is explored in the next paper. 
Diego Mattos, Rafael Ariente Neto, Eugenio Merino and Fernando Forcellini describe a production system using Systems Dynamics modelling. This provides an opportunity to explore the relations between system components and also provide a means of testing these relations through modelling. The models allow complicated relationships to be captured and the paper shows how it is possible to reflect some of the emergent properties of the dynamic operation of a system. This provides a first step to describing systems as dynamic entities. However, the mathematical analysis that underpins Systems Dynamics Models tends to rely on linear (one-to-one) correspondences between components. This contrasts with a desire to understand and create nonlinear models of Dynamic Systems, which are the focus of the quantitative methods in this Special Issue.

\section{Quantitative Methods}

Understanding nonlinear dynamics is essential to the new Ergonomics that are being presented in this Special Issue. In simple situations there might be a one-to-one mapping between a cause and effect. In such cases, the cause has a linear relationship to be made with an effect, and so, knowing the cause allows you to predict the effect. Ergonomics tends to deal with situations in which there are manyto-many mappings which means that, even if you can identify a single 'cause', it is unlikely that this can predictably result in a single 'effect'. Rather, the relations between cause and effect are nonlinear. We have three papers that describe and illustrate a range of techniques that offer potential to describe systems from this perspective.

Stephen Guastello demonstrates the use of a cusp catastrophe modelling to explore ways in which work demands (relating to workload and to fatigue) are responded to through coping strategies under different temporal and practice conditions. Catastrophe models illustrate how small changes in the parameters that define the state of a 'system' (in this case, the system is an emergency response team) can have sudden effects on measures of activity. From a cybernetics perspective, we could claim that a system is using its feedback loops to achieve some level of stability, or equilibrium. Catastrophe models describe how changes in system state, to an equilibrium, can occur suddenly but, prior to this change, there could be an increase in the variability of activity. In other words, rather than making a smooth transition from one state to another, there could be an increase in unpredictable and unstable activity. Such a phenomena can be applied, at an individual level, to changes in workload and fatigue with changing task demands. Guastello elaborates this concept and demonstrates its application to teams.

Travis Wiltshire, Sune Steffensen and Stephen Fiore also look at team dynamics. In their study, teamwork focuses on the coordination of collaborative problem solving. Specifically, their analysis looks at pairs of people using NASA's moonbase alpha task and the ways in which body motion (automatically analysed from video recordings) of team members can be used to infer coordination and collaboration. Using cross - wavelet coherence and growth curve modelling, the authors suggest that movement in the $.25 \mathrm{~s}$ to $2 \mathrm{~s}$ range were significantly coordinated (although movements on longer timescales also show potential for coordination). Of particular interest is the idea that one can automate the monitoring of team members in order to determine the degree of coordination that they are exhibiting, and that this can be reliably achieved by focussing on movement without analysing the specific tasks performed or the content of their communication.

Waldemar Karwowski, David Kern, Atsuo Murata, Tareq Ahram, Edgar Gutierrez Franco and Nabi Sapkota apply time-series analysis techniques (specifically, 1/f scaling, Largest Lyanpunov Exponent and fractal dimensions) to data derived from standing watch on naval vessels. The results indicate the applicability of these measures and further support the suggestion that human performance can be described in terms of its complex adaptive response to situational demands. 


\section{Conclusions}

For all of these papers, the central question lies in the definition, measurement and interpretation of variability in system performance. The papers illustrate different approaches to analysing these timevarying phenomena. For Applied Ergonomics the central messages are that, rather than seeking to remove variability (by, for example, looking for ways to reduce the description of system performance to some measure of central tendency, such as mean time to complete a task), we should be asking how system performance changes over time; making sense of the stability and variability of system performance, then raises questions of how the system might be exercising control, i.e., what are the parameters that the system appears to be optimising (which, as Hancock, noted, might not be the parameters that the designers, managers or operators believe they are controlling); and in seeing systems as complex, adaptive and continually responding to situational demands. It is these points that will allow Ergonomics to shift from the recognition that systems can be described in the static representations of diagrams to the more powerful ability to describe the dynamics of these systems.

\section{References}

Anon, (1972). The Department of Ergonomics and Cybernetics, Loughborough University of Technology. Applied Ergonomics, 2, 1, 44-55.

Ashby, W.R. (1948). Design for a brain. Electronic Engineering, 20 (December), 379-383..

Ashby, W.R. (1956). An introduction to cybernetics. London: Methuen.

Bateson, G. (1972). Steps to an Ecology of Mind. New York: Ballantine.

Beer, S. (1966). Decision and control. Chichester: Wiley.

Beer, S. (1975). Laws of Anarchy. In D. Whittaker. Ed. Think before you think: social complexity and knowledge of knowing. Wavestone press. Charlbury, UK.

Beer, S. (1981). Brain of the firm. Chichester: Wiley.

Braithwaite, J. (2018). Changing how we think about healthcare improvement. British Medical Journal, 361.

Burr, T., Merrifield, S., Duffy, D., Griffiths, J., Wright, S., \& Barker, G. (2008). Reducing passenger rail delays by better management of incidents. National Audit Office for the Office of Rail Regulation.

Clark, A. (2008). Supersizing the Mind: Embodiment, Action, and Cognitive Extension. Oxford: Oxford University Press.

Conant, R. C. \& Ashby, W. R. (1970). Every good regulator of a system must be a model of that system, International Journal of Systems Science, 1, 89-97.

Dekker, S. (2011), Drift Into Failure: From Hunting Broken Components to Understanding Complex Systems. Farnham: Ashgate.

Eason, K.D. and Waterson, P.E. 920140. Fitness for purpose when there are many different purposes: Who are electronic patient records for? Health Informatics Journal, 3, 189-198.

Edwards, E. and Lees, F. (1974). The Human Operator in Process Control. London: Taylor and Francis

Feltovich, P. J., Hoffman, R. R., Woods, D., \& Roesler, A. (2004). Keeping it too simple: How the reductive tendency affects cognitive engineering. IEEE Intelligent Systems, 19(3), 90-94.

Golightly, D., Dadashi, N., Sharples, S., \& Dasigi, M. (2013). Disruption management processes during emergencies on the railways. International Journal of Human Factors and Ergonomics, 2(2-3), 175195.

Golightly, D., \& Dadashi, N. (2017). The characteristics of railway service disruption: implications for disruption management. Ergonomics, 60(3), 307-320.

Guastello, S., this issue, Cusp Catastrophe Models for Cognitive Workload and Fatigue in Teams

Hancock, P., this issue, The Humane Use of Human Beings?

Hollnagel, E., Braithwaite, J. \& Wears, R. L. (Eds.) (2013). Resilient Health Care. Farnham, UK: Ashgate.

Hollnagel, E, Woods, D. D. (2005). Joint cognitive systems: Foundations of cognitive systems engineering. CRC Press. 
Husbands, P. and Holland, O. (2008), The Ratio club: a hub of British cybernetics. In P. Husbands, M. Wheeler, and O. Holland, Owen, (Eds.) The Mechanical Mind in History. Cambridge, Mass: MIT Press.

Karwowski, W., Kern, D., Murata, A., Ahram, T., Franco, E.G. and Sapkota, N., this issue, Complexity of Human Performance Variability on Watch Standing Task

Kirkup, B. (2015). The Report of the Morecambe Bay Investigation. Available from: https://www.gov.uk/government/publications/morecambe-bay-investigation-report accessed October 3rd, 2018).

Kleiner, B. and Hendrick, H.W. (2002), Macroergonomics: Theory, Methods, and Applications. London: CRC Press.

Leveson, N. (2012). Engineering a Safer World. Cambridge: MIT Press.

Madigan, R., Golightly, D., \& Madders, R. (2016). Application of human factors analysis and classification system (HFACS) to UK rail safety of the line incidents. Accident Analysis \& Prevention, 97, 122-131.

Mattos, D., Neto, R.A., Merino, E. and Forcellini, F., this issue, Simulating the influence of work overload on assembly line performance: a case study in an automotive electrical component plant

Morineau, T. and Flach, J., this issue, The heuristic version of Cognitive Work Analysis: a first application to medical emergency situations

Office of Rail and Road (2016) Passenger Rail Service Complaints 2016-17 Q4 Statistical Release Available from http://orr.gov.uk/_data/assets/pdf_file/0006/24927/passenger-rail-servicecomplaints-2016-17-q4.pdf

Pask, G. (1975). The Cybernetics of Human Learning and Performance. London: Hutchinson.

Pickering, A. (2010). The Cybernetic Brain - Sketches of Another Future. Chicago: Chicago University Press.

Plsek, P.E. and Greenhalgh, T. (2001). The challenge of complexity in health care. British Medical Journal, 323:625.

Rasmussen, J. (1997). Risk management in a dynamic society: a modelling problem, Safety Science, 27, 183-213.

Schipper, D. (2017). Challenges to multiteam system leadership: an analysis of leadership during the management of railway disruptions. Cognition, Technology \& Work, 19(2-3), 445-459.

Tang, T., Li, C., Chatzmilicahilidou, M.M., Tan, G.T., and Waterson, P., this issue, A hybrid human and organisational analysis method for railway accidents based on STAMP-HFACS and Human information processing

Turner, B.A. (1978). Man-Made Disasters. London: Wykeham Press.

Underwood, P. and Waterson, P.E. (2013). Systemic accident analysis: examining the gap between research and practice. Accident Analysis and Prevention, 55, 154-164.

Waterson, P.E. (2011), World War II and other historical influences on the formation of the Ergonomics Research Society. Ergonomics, 54, 12, 1111-1129.

Waterson, P.E. and Le Coze, J-C. (2017), Two different qualitative cyberneticians: Barry Turner and Jens Rasmussen. In A. Bertanikm L. Kocurokova and K. Jorgensen (Eds.) Prevention of Accident at Work. Boca Raton: CR Press.

Waterson, P.E., Baber, C. and Li, C. (2016). How viable is STAMP? Comparing STAMP with Beer's Viable Systems Model (VSM) using the China-Yongwen railway accident as an example. Presentation at Human Factors in Complex Systems symposium, Nottingham.

Wiener, N. (1948). Cybernetics, or control and communication in the animal and the machine. Cambridge, MA: MIT Press.

Wilson, J. R., Farrington-Darby, T., Cox, G., Bye, R., \& Hockey, G. R. J. (2007). The railway as a sociotechnical system: human factors at the heart of successful rail engineering. Proceedings of the Institution of Mechanical Engineers, Part F: Journal of Rail and Rapid Transit, 221(1), 101-115.

Wilson, J.R. (2014). Fundamentals of systems ergonomics/human factors. Applied Ergonomics, 45, 513.

Wiltshire, T., Steffensen, S.V. and Fiore, S.M., this issue, Multiscale Movement Coordination Dynamics in Collaborative Team Problem Solving 
Woods, D. D., \& Hollnagel, E. (2005). Joint cognitive systems: Foundations of cognitive systems engineering. CRC Press. 